\title{
Endodontic Irrigation: A Survey among Tunisian Dentists Practicing in Private Clinic
}

Rim Ragoubi ${ }^{1 *}$, Imène Gnaba ${ }^{2}$

${ }^{1}$ Resident, Faculty of Dental Medicine of Monastir, University of Monastir, Department of Dental Medicine, Hospital Charles Nicolle, Bd du 9 Avril 1938, Tunis, Tunisia

${ }^{2}$ Associate Professor, Department of Dental Medicine, Farhat Hached Hospital, Sousse, Tunisia

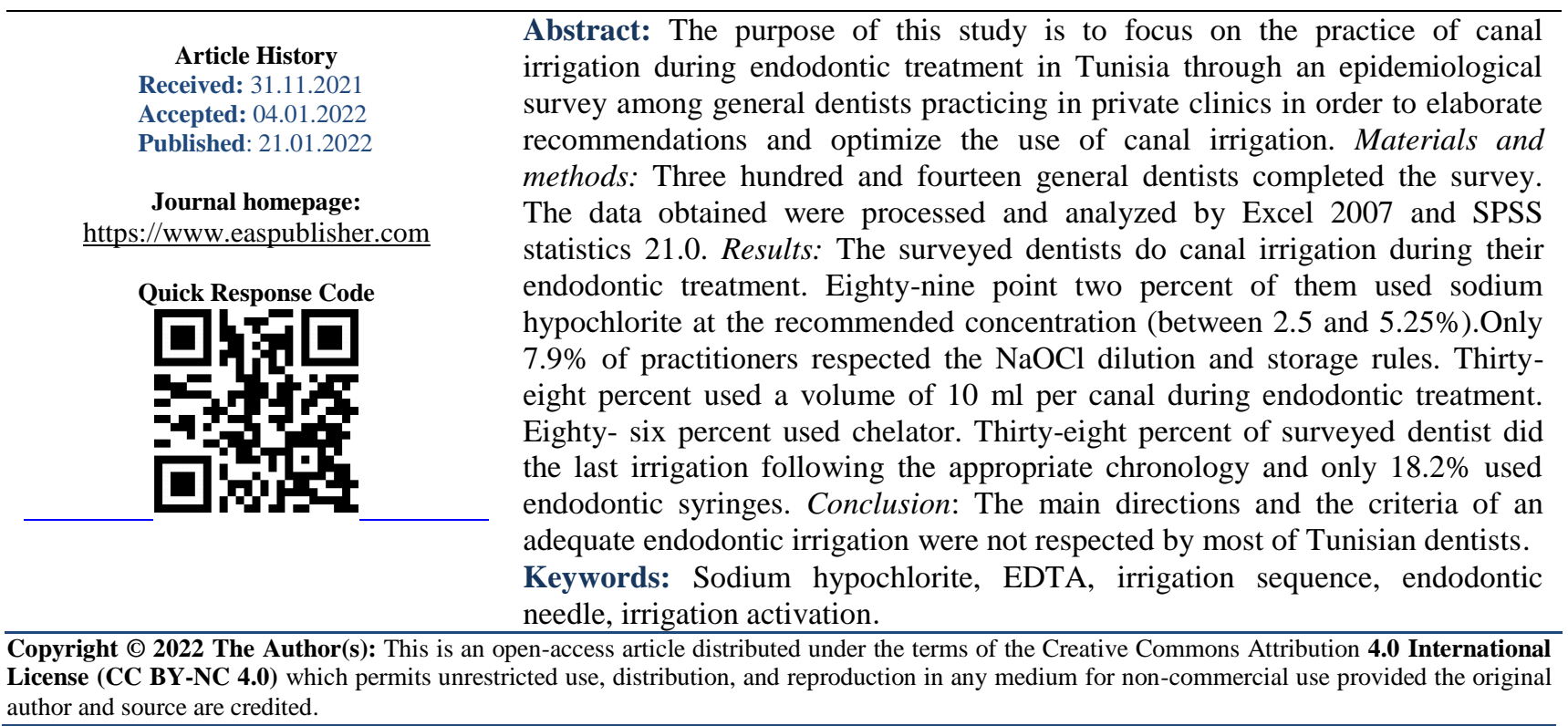

\section{INTRODUCTION}

Successful root canal treatment based on the endodontic triad: disinfection in three dimensions, shaping and feeling root canal systems (Abuhaimed TS et al., 2017) (Adou-Assoumou NM et al., 2010).

Shaping the root canal system is an essential step to remove contents and prepare the canal for filling. This step will remove organic debris and create the necessary path for irrigants that ensure chemical disinfection by bringing the irrigant to the root canal system renewing and activating it to get complete disinfection and increase the success rate (Abuhaimed TS et al., 2017) (van der Waal SV et al., 2014).

Irrigation is an essential step in endodontic treatment, it reduces the number of bacteria and contributes to the healing of root canal area (Haapasalo M, et al., 2014)

Hence, our goal is to check current trends of irrigation among dentists practicing in private clinics, discuss some of the mistake made during root canal treatment to provide some recommendations.

\section{Materials AND MethodS}

A self-prepared survey was shared via Google forms to five hundred and twenty Tunisian doctors practicing in private clinics.

The survey was made of 32 questions. The first part was about the profile of dentists who accepted to share their experiences. The second part was about endodontic treatment, irrigant selection, concentration and smear layer removal, materials used in irrigation, and final irrigation. Questions consisted of numeric ranking, QCM and multiple selections to express and write about background knowledge.

The survey ended after three months and ten days. The data were compiled and analysed by statistical software SPSS and EXCEL 2007.

\footnotetext{
*Corresponding Author: Rim Ragoubi

Resident, Faculty of Dental Medicine of Monastir, University of Monastir, Department of Dental Medicine, Hospital Charles Nicolle,
} Bd du 9 Avril 1938, Tunis, Tunisia 


\section{RESULTS}

Out of 520 Google forms links were e- mailed and sent via social media only 314 were received. The return rate was about $60.38 \%$.
Informations about irrigants used by Tunisian dentist

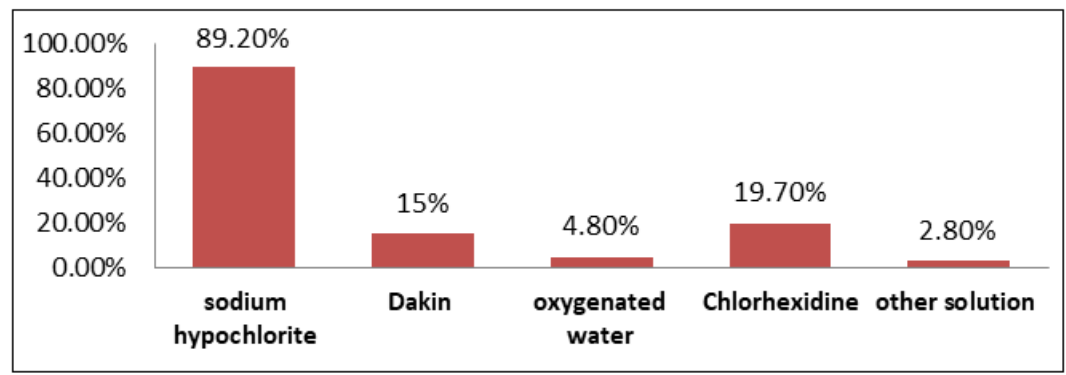

Figure 1: Distribution according to irrigation solution

Table 1: Main characteristics of sodium hypochlorite used by the majority of surveyed dentists

\begin{tabular}{|l|l|}
\hline Sodium hypochlorite (SH) & Percentage \\
\hline Knowledge of Method of dilution & $60 \%$ \\
\hline Product of dilution =distiled water & $29 \%$ \\
\hline Storage time =24 hours & $53 \%$ \\
\hline Concentration $=3 \%$ & $31.2 \%$ \\
\hline Opac trank for SH storage & $60 \%$ \\
\hline
\end{tabular}

According to this survey, sixteen percent of dentists who used sodium hypochlorite diluted admitted their grasp of the method of dilution $.60 \%$ used tap water for dilution and only twenty nine percent used distilled water and twelve percent used physiological serum for dilution. Our survey showed that $31.2 \%$ Used sodium hypochlorite with Three percent concentration,
$27 \%$ used $2.5 \%, 13.9 \%$ used $2.25 \%$ and $27.1 \%$ ignore the concentration of sodium hypochlorite that they used.

$53 \%$ kept sodium hypochlorite for one day and $60 \%$ used an opac trank for storage of SH but $4 \%$ used a metallic trank for storage (Table 1).

Table 2: Cross-tables: method of dilution * (storage environment + storage time + dilution product) Sodium Hypochlorite Opaque trank +storage time :One day +dilution product:distilled watter \begin{tabular}{|l|l|}
\hline Dillution method:Yes & $7.9 \%$ \\
\hline
\end{tabular}

In this survey, $7.9 \%$ among $60 \%$ of practitioners admitted their grasp of $\mathrm{SH}$ dilution method, used distilled water for dilution and kept $\mathrm{SH}$ in an opac trank for one day (Table 2).

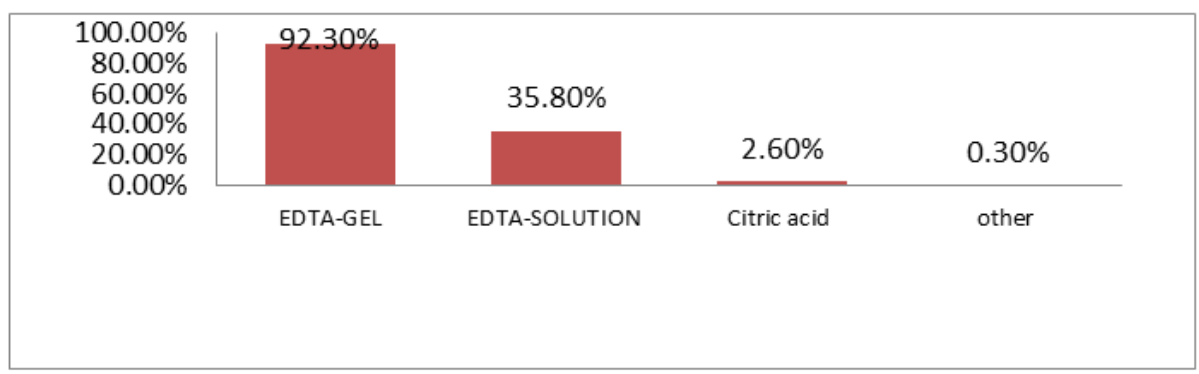

Figure 2: Distribution according using chelator

Also, it showed that $92.3 \%$ used EDTA-GEL as a chelator, $35.8 \%$ used EDTA solution, $2.6 \%$ used citric acid and $0.3 \%$ used other solution (Figure 2).
$58 \%$ used EDTA gel for root canal negotiation and $51 \%$ Used EDTA-SOLUTION in final irrigation. 


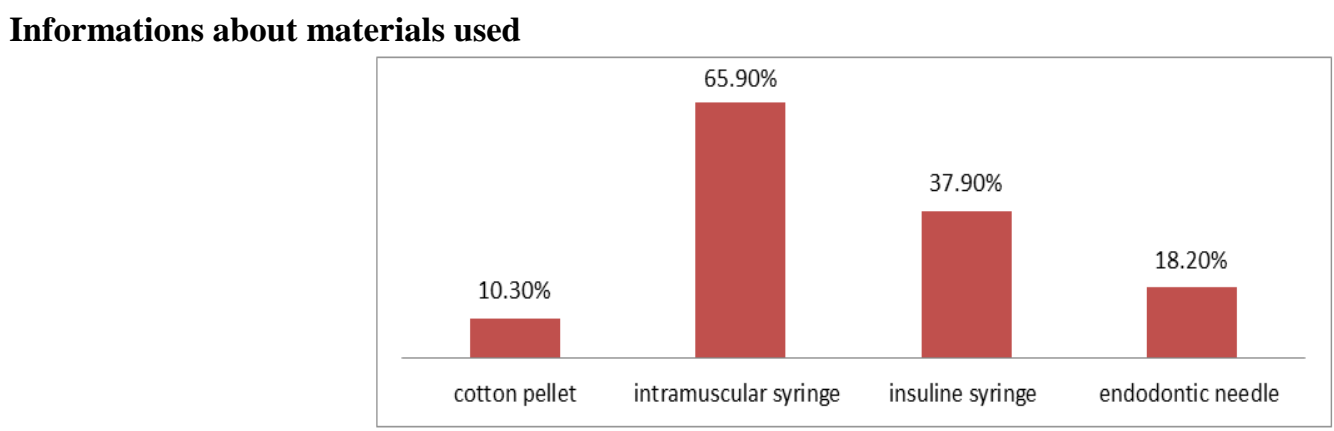

Figure 3: Information about materials of irrigation

$65.9 \%$ used intramuscular syringe, $37.9 \%$ used insulin syringe, $18.2 \%$ used endodontic needle and $10.3 \%$ used cotton pellet for irrigation (Figure 3).

\section{Informations about irrigation method}

In this study $90.8 \%$ announced that they did root canal irrigation in every stage of endodontic treatment and only $37.9 \%$ used final irrigation. $38 \%$ of surveyed dentist used $10 \mathrm{ml}$ of irrigant per root canal and only $38 \%$ of practitionrs did a final irrigation. $41 \%$ of the dentists activated the irrigant (Figure 4), 67.9\% used manuel activation, $31.1 \%$ used ultrasonic and only 9.8\% used laser (Figure 5).

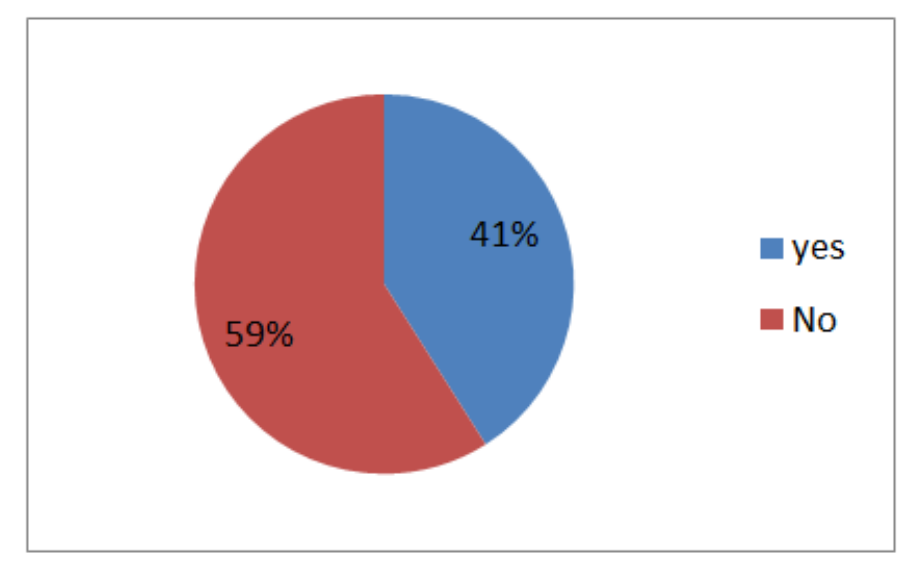

Figure 4: Distribution according to irrigant activation

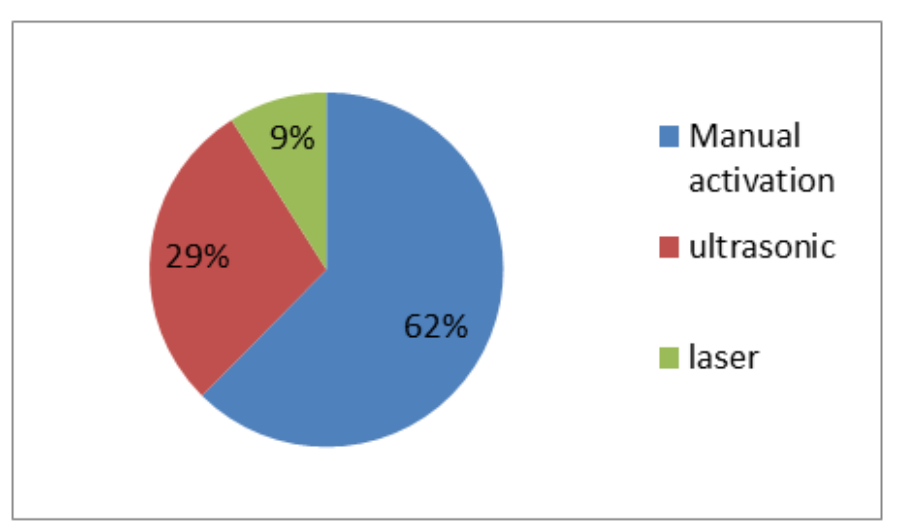

Figure 5: Distribution according to activation technique

\section{DISCUSSION}

\section{Informations about irrigant used by Tunisian dentist:}

The majority of Tunisian dentist used $\mathrm{SH}$ as a principal irrigant. These results were in agreement with reports from the literature, Turkish survey in 2012, German survey 2014 (Willershausen I et al., 2015) (Kaptan RF et al., 2012). The majority "31.2\%" stated they used $3 \% \mathrm{NaOCl}$ solution, similar results " $55.4 \%$," were reported by German survey in 2014. (Willershausen I et al., 2015) Indeed, the effectiveness of SH depends on the quantity of hypochlorous acid available, which is directly related to the concentration of the solution. For disinfection, the minimum concentration of $\mathrm{NaOCl}$ solution was $0.5 \%$ and $1 \%$ for the dissolving effect (van der Waal SV et al., 2014) The concentration used varied between 2.5 and $5.25 \%$. A 
concentration of 2.5 to $3 \%$ seems to be the most adequate to limit the cytotoxic effect of $\mathrm{NaOCl}$ solution (6).
According to our survey, $29 \%$ used rubber dam, this result was compared with other studies in the USA, China, Saudi Arabia, Virginia as shown in the following table:

Table 3: Comparison of similar surveys regarding the use of the rubber dam

\begin{tabular}{|l|l|l|l|l|}
\hline Countries & $\begin{array}{l}\text { USA (Lawson NC, } \\
\text { 2015) }\end{array}$ & $\begin{array}{l}\text { China (Zou H } \text { et } \\
\text { al., 2016) }\end{array}$ & $\begin{array}{l}\text { S.Arabia (Madarati } \\
\text { AA., 2016) }\end{array}$ & $\begin{array}{l}\text { Virgina (Imbery } \\
\text { TA, 2019) }\end{array}$ \\
\hline Year of study & 2014 & 2016 & 2016 & 2019 \\
\hline The use of rubber dam & $60 \%$ & $63.3 \%$ & $21.6 \%$ & $37.2 \%$ \\
\hline
\end{tabular}

The use of a rubber dam is still not used as required, although it has been taught at the dental faculty of Monastir.

According to our survey, only $9.7 \%$ of surveyed dentists who admitted their understanding of dilution method used distilled water for dilution, kept $\mathrm{SH}$ in an opak non-metallic trank for one day. In fact, $\mathrm{SH}$ is an unstable solution because several parameters accelerate the degradation of available chlorine, namely (Université Laval, 2020).

- The presence of metals and impurities in the solution. A metal tank is therefore not recommended.

- The $\mathrm{pH}$ of the solution.

- The temperature of the solution.

- Exposure to sunlight (ultraviolet rays).

- Storage time of the solution, which should be as short as possible.

Our study showed that $86 \%$ of dentists used a chelator during root canal treatment. Most of practitioners used EDTA gel with a percentage of $92.3 \%$ while only $35.8 \%$ used EDTA-solution.

A survey of members of the American Association of Endodontists showed that $80 \%$ of them used EDTA during root canal irrigation (Guivarc'h $\mathrm{M}$ et al., 2015). In fact, $\mathrm{SH}$ is inactive on the smear layer, because it is unable to dissolve the mineral parts. Therefore, it must be coupled with a chelating agent such as EDTA (Mohammadi Z et al., 2017).

Our study showed that more than half of the dentists ("58\%") who used chelator agent used EDTA gel during catheterization.

The real contribution of these products during catheterization or preparation of thin and/or calcified canals is well documented and its use must be reserved with instruments that present sharp edges (Guivarc'h M et al., 2015).

According to this survey $51 \%$ used EDTA solution in final irrigation this result can be explained by the high cost of this liquid or the ignorance of its clinical interest in final irrigation.
Indeed, once the root canal shaping is completed a chelating solution can be used to remove the smear layer (Guivarc'h M et al., 2015). Liquid EDTA is generally used at a concentration of $17 \%$, the solution can remove the smear layer when it comes into contact with the root canal walls within $1 \mathrm{~min}$ (Doumani M et al., 2017).

\section{Informations about material of irrigation}

This survey showed that $18.2 \%$ used endodontic needles in irrigation similar result was reported by a survey conducted in Abidjan, the minority, only $7 \%$, used endodontic needles. Indeed, the use of non-endodontic syringes is strongly not recommended (Adou-Assoumou NM et al., 2010).

Concerning the choice of the syringe, currently, the "Luer Lock" model is the only one recommended because it avoids the detachment of the needle during root canal irrigation and secures its refill (Nastorg AM, 2019).

\section{Informations about method of irrigation}

The frequence of renewal of the irrigant after using each file observed in this study for $90.8 \%$ in accordance with HAS (haut autorité de la santé).Similar results is reported by a survey conducted in Abidjan in 2010 (Adou-Assoumou NM et al., 2010).

Only $38 \%$ percent of surveyed dentist used $10 \mathrm{ml}$ of irrigant per canal which is in accordance with HAS recommendations which call for $1 \mathrm{ml}$ to be renewed after each file (Adou-Assoumou NM et al., 2010). Thirty-eight percent of surveyed dentist who do final irrigation following the appropriate chronology and only $41 \%$ of surveyed dentists activate the irrigant, similar result $34 \%$ was reported by a survey was conducted in Nouvelle Aquitaine in 2019 (Kaptan RF et al., 2012).

In fact, Activation improves the penetration of the solution into the root canal system, especially in areas that cannot be instrumented by mechanical shaping. Activation of the irrigation solution also promotes the renewal of the solution and improves its Functions.

\section{RECOMMENDATIONS}

- The ruber dam must be used before endodontic 
treatment.

- $\quad \mathrm{SH}$ must be used with concentration varies between $2.5 \%$ and $5.25 \%$.

- $\mathrm{SH}$ must be dilueted with distilled water and kept in dark for 24 hours.

- After using SH netrelize the root canal with saline solution before using EDTA or Chlorhexidine.

- Use EDTA-solution $17 \%$ in final irrigation to eliminate smear layer.

- Use an endodontic needle with a diametre 28 or 30 $/ 100$ of millimiters with luer lock syringe for irrigation.

- Activate root canal irrigation.

- A final irrigation could be done as shown in the following diagram.

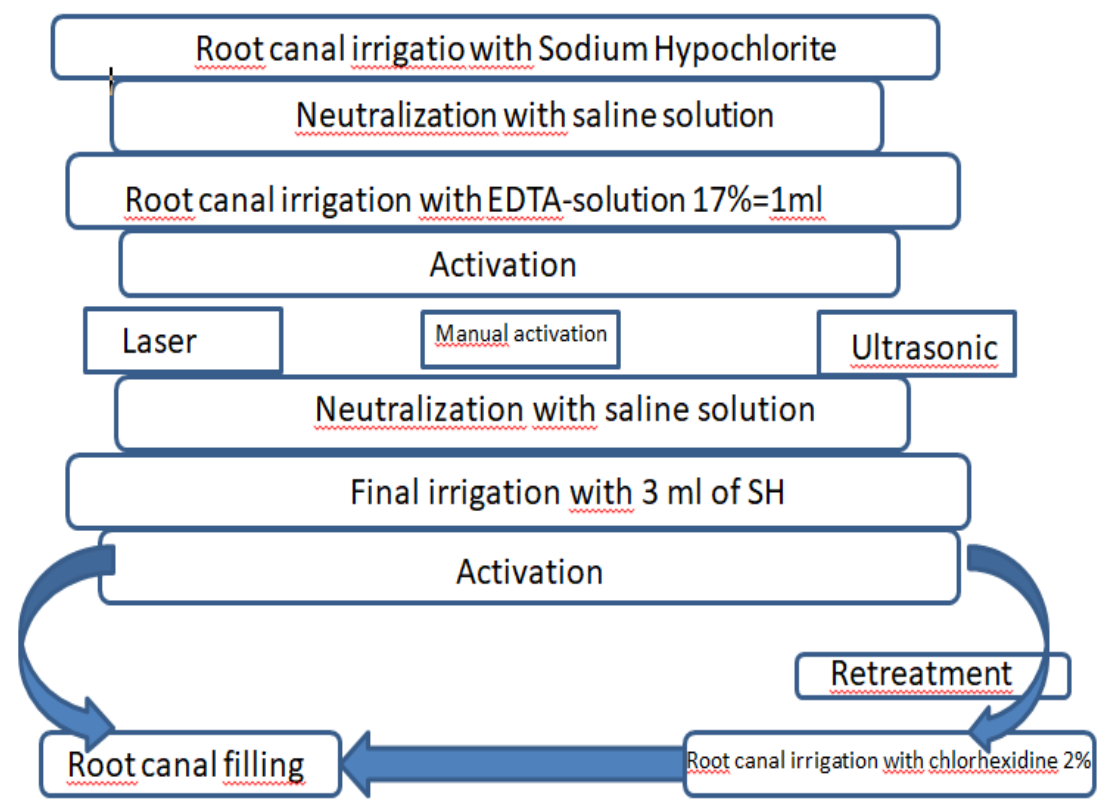

Figure 6: Final irrigation sequence

\section{CONCLUSION}

The main directions as well the criteria of an adequate endodontic irrigation were not respected by the majority of Tunisian dentists.

\section{REFERENCES}

- Abuhaimed, T. S., \& Abou Neel, E. A. (2017). Sodium hypochlorite irrigation and its effect on bond strength to dentin. BioMed research international, 2017.

- Adou-Assoumou, N. M., Sinan-Krah, A. A., Kouakou, K., Thiémélé-Yacé, S. E., \& Ablé, O. (2010). Enquête Sur La Pratique De L'irrigation Endocanalaire À Abidjan. Rev Odontostomatol, 12, 25-31.

- $\quad$ van der Waal, S. V., van Dusseldorp, N. E., \& de Soet, J. J. (2014). An evaluation of the accuracy of labeling of percent sodium hypochlorite on various commercial and professional sources: is sodium hypochlorite from these sources equally suitable for endodontic irrigation?. Journal of endodontics, 40(12), 2049-2052.

- Haapasalo, M., Shen, Y., Wang, Z., \& Gao, Y. (2014). Irrigation in endodontics. British dental journal, 216(6), 299-303.

- Willershausen, I., Wolf, T. G., Schmidtmann, I., Berger, C., Ehlers, V., Willershausen, B., \&
Briseño, B. (2015). Survey of root canal irrigating solutions used in dental practices within Germany. International Endodontic Journal, 48(7), 654-660.

- Simon, S. (2011). L'irrigation en endodontie: l'essentiel à connaître à tout prix. Clinic Février.

- Lawson, N. C., Gilbert, G. H., Funkhouser, E., Eleazer, P. D., Benjamin, P. L., Worley, D. C., \& National Dental PBRN Collaborative Group. (2015). General dentists' use of isolation techniques during root canal treatment: from the national dental practice-based research network. Journal of endodontics, 41(8), 1219-1225.

- Zou, H., Li, Y., Lian, X., Yan, Y., Dai, X., \& Wang, G. (2016). Frequency and influencing factors of rubber dam usage in Tianjin: A questionnaire survey. International journal of dentistry, 2016.

- Madarati, A. A. (2016). Why dentists don't use rubber dam during endodontics and how to promote its usage?. BMC oral health, 16(1), 1-10.

- Imbery, T. A., \& Carrico, C. K. (2019). Dental dam utilization by dentists in an intramural faculty practice. Clinical and experimental dental research, 5(4), 365-376.

- Université Laval. Gestion des solutions d'hypochlorite de sodium recommandations à l'intention des opérateurs de petites installations de 
production d'eau potable. (2020). Retrieved Mars,62020, from http://www.environnement.gouv.qc.ca/eau/potable/ brochure/gestion-solutions-hypochlorite.pdf

- Mohammadi, Z., Shalavi, S., Moeintaghavi, A., \& Jafarzadeh, H. (2017). A review over benefits and drawbacks of combining sodium hypochlorite with other endodontic materials. The open dentistry journal, 11, 661-669.

- Guivarc'h, M., \& Bukiet, F. (2015). Place des agents chélateurs dans l'irrigation canalaire en endodontie. Alpha Omega, 172, 12-13.

- Doumani, M., Habib, A., Doumani, A., \& Kinan, M. (2017). A review: the applications of EDTA in endodontics (Part I). IOSR Journal of Dental and Medical Sciences, 16(9), 83-85.
- Boutsioukis, C., Kastrinakis, E., Lambrianidis, T., Verhaagen, B., Versluis, M., \& van der Sluis, L. W. M. (2014). Formation and removal of apical vapor lock during syringe irrigation: a combined experimental and Computational Fluid Dynamics approach. International endodontic journal, 47(2), 191-201.

- Nastorg, A. (2019). L'activation de la solution d'irrigation en endodontie: quelle place dans les pratiques libérales en Nouvelle-Aquitaine? [Thèse]. Bordeaux: Unité de formation et de recherche d'odontologie de Bordeaux.

- Kaptan, R. F., Haznedaroglu, F., Kayahan, M. B., \& Basturk, F. B. (2012). An investigation of current endodontic practice in Turkey. The Scientific World Journal, 2012.

Cite This Article: Rim Ragoubi \& Imène Gnaba. Endodontic Irrigation: A Survey among Tunisian Dentists Practicing in Private Clinic. EAS J Dent Oral Med, 4(1), 1-6. 